CVIA

REVIEW ARTICLE

pISSN 2508-707X / elSSN 2508-7088 https://doi.org/10.22468/cvia.2016.00122 CVIA 2017;1(2):124-132

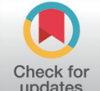

Received: November 22, 2016

Revised: January 24, 2017

Accepted: February 8, 2017

Corresponding author

Lilian LY Leong, Founding President

Hong Kong College of Radiologists,

Room 909, 9/F, Hong Kong

Academy of Medicine Jockey Club

Building, 99 Wong Chuk Hang Road,

Aberdeen, Hong Kong

Tel: 852-2871-8788

Fax: 852-2554-0739

E-mail: Iflyleong@gmail.com

\section{Imaging of Congenital Heart Disease} in Hong Kong: From Invasive to Non-invasive Cardiac Imaging

\author{
Kin Sun TSE, Janice JK Ip, Lilian LY Leong \\ Department of Radiology and Imaging, Queen Elizabeth Hospital, Kowloon, Hong Kong
}

\begin{abstract}
Congenital heart disease (CHD) is a major global health issue. In Hong Kong, left-to-right shunting, pulmonary outflow obstruction including tetralogy of Fallot, followed by left ventricular outflow obstruction and coarctation of aorta, are the most commonly encountered congenital heart defects. Imaging has played an important role in the diagnosis, treatment planning, and follow up of patients with CHD. The advances in the techniques of non-invasive imaging modalities have led a revolutionary change in the diagnosis and management of CHD. Advanced echocardiography e.g., speckle tracking technique, pixel tracking technique, velocity vector imaging, and 3-dimensional (3D) echocardiography; computed tomography; and magnetic resonance imaging have been widely applied. The field of 3D printing has superb advantages in illustrating complex congenital heart defects, and thus allows individualized modeling and accurate treatment planning.
\end{abstract}

Key words Congenital heart disease - Echocardiography · CT · MR ·

3-dimensional prototyping and modeling.

\section{BACKGROUND}

Congenital heart disease (CHD) is the most common major congenital anomalies [1]. The world birth prevalence of $\mathrm{CHD}$ is currently estimated to be 9.1 per 1,000 live births after year 1995 [2]. Geographic variations have been observed, ranging from the highest prevalence in Asia at 9.3 per 1,000 live births (e.g., in Taiwan at 9.18 per 1,000 children and with severe CHD at 1.07 per 1,000 [3]) to lower prevalence in Europe at 8.2 per 1000 live births. The variation is attributed to the discrepancies in case definition and identification, advances and availability of diagnostic modalities, hereditary and environmental factors [2].

In Hong Kong, a local cross-sectional study revealed that the estimated incidence of CHD was at 6.35 per 1,000 live births [4]. This result was inferred from the clinical and echocardiographic assessment of newborn babies suspected of CHD in a regional hospital from 1987 to 1989, but it might have underestimated its true prevalence. Left-to-right shunting was the most common congenital heart defect (45.0\%), followed by pulmonary outflow obstruction [including tetralogy of Fallot (TOF) and Critical Pulmonary Stenosis] (34.4\%), which was more prevalent than in Western countries $[5,6]$. Coarctation of aorta

(c) This is an Open Access article distributed under the terms of the Creative Commons Attribution Non-Commercial License (http://creativecommons.org/licenses/bync/4.0) which permits unrestricted non-commercial use, distribution, and reproduction in any medium, provided the original work is properly cited. accounted for about $5 \%$ of all CHDs, but left ventricular (LV) outflow tract obstruction (8.3\%) was in general less common in local Chinese population $[5,6]$. As in Guangdong province in China, our geographic neighbor, left-to-right shunt takes up the largest proportion of CHD, with ventricular septal defect being the commonest, followed by patent ductus arteriosus and atrial septal defect [7]. A lower incidence of LV outflow obstruction is again observed in Guangdong province [7]. The insignificant difference in the incidence of pulmonary outflow obstruction and transposition of great arteries is not observed in our locality [7].

Symptomatic CHD was not only associated with intrauterine growth retardation [8], but also postnatal wasting and stunting among local Chinese paediatric patients [9]. With increased survival rate among patients with CHDs, the expansion of adult population with $\mathrm{CHD}$ therefore poses a major global health problem [10].

\section{CARDIAC CATHETERIZATION AND ECHOCARDIOGRAPHY}

Cardiac catheterization and cineangiography had been the major diagnostic tool for CHD before 1990's. Cardiac catheterization allowed delineation of intracardiac and extracardiac vascular anatomy, measurement of intracardiac pressure, calcu- 
lation of blood flows and shunts, and estimation of blood gas; and aided the diagnosis of congenital heart defects [11]. Nevertheless, paediatric cardiac catheterization was associated with various major complications, including arrhythmia, vascular thrombosis, bleeding, catheter manipulation-related complications, and rarely death, in particular among neonates and young children $[12,13]$. This has led to the development and application of non-invasive examinations for CHD in Hong Kong (Table 1).

The application of the echocardiography has revolutionized the imaging of $\mathrm{CHD}$ and marked the era of noninvasive imaging. Being non-invasive and readily available, echocardiography has become the most commonly used imaging modality to assess the functional aspects of the heart in Hong Kong since 1980's. The earlier applications of echocardiography with $\mathrm{M}$ mode assessment and 2D methods including Simpson algorithm were mainly on LV shortening fraction and systolic function, as well as volumetric assessment. Pulse-wave Doppler examination was also utilized to evaluate the $\mathrm{LV}$ diastolic function, by analyzing the mitral early (E) and late (A) diastolic inflow velocities. In an earlier study at Grantham Hospital in Hong Kong, a territorywide referral center for surgical treatment of paediatric $\mathrm{CHD}$, the combined cross-sectional echocardiography and pulsed Doppler flow study had been successfully utilized for the assessment of paediatric CHD in 1980's [14]. Echocardiography had allowed clear definition of the anatomy at all cardiovascular junctions by sequential segmental approach in symptomatic neonates suspected of having $\mathrm{CHD}$, with a high diagnostic sensitivity and specificity at $95.5 \%$ and $98.6 \%$ respectively, and thus reducing the use of diagnostic catheterization in making manage- ment decisions [15]. The pulsed-wave Doppler examination was an adjunctive tool in diagnosing extracardiac vascular anomalies and valvular dysfunction, as well as detecting ductus arteriosus and abnormal systemic venous channels [15]. Based on their experience, only $20 \%$ of paediatric patients required additional cardiac catheterization for planning treatment, which was mainly reserved for extra cardiac vascular structures $[15,16]$.

Adoption of intra-operative echocardiography since 1980's had contributed to the success of various cardiac interventions in treating paediatric CHDs in Hong Kong. Transthoracic echocardiography had been utilized to monitor balloon atrial septostomy in neonates in 1980's [17]. Echocardiography offered clear delineation of cardiac anatomy and directed catheter manipulation. The introduction of intra-operative transesophageal echocardiography since early 1990's had also guided certain cardiac procedures on the interatrial septum, including occlusion of ASD, trans-septal puncture and blade septectomy, as well as balloon valvuloplasty and angioplasties in children [18].

\section{ADVANCED ECHOCARDIOGRAPHY}

Echocardiography has been one of the primary cardiac imaging modalities, but it has weaknesses. It is limited by a small field of view, an acoustic window, and operator dependence. Strain and strain rate imaging has been rapidly developing in the past few years as a quantitative method to precisely estimate myocardial contractility and function. In particular, non-Doppler twodimensional (2D) strain is a new echocardiography technique that is used to obtain strain and strain rate measurements. This technique analyzes motion through tracking speckles in a $2 \mathrm{D}$

Table 1. Overview of non-invasive cardiac examinations for evaluation of congenital heart disease

\begin{tabular}{|c|c|c|}
\hline & Advantages & Disadvantages \\
\hline $\begin{array}{l}\text { Conventional } \\
\text { echocardiography }\end{array}$ & $\begin{array}{l}\text { 1. Non-invasive, real time examination } \\
\text { 2. Sedation not required } \\
\text { 3. Allow evaluation of left ventricular systolic and } \\
\text { volumetric assessment }\end{array}$ & $\begin{array}{l}\text { 1. Small field of view } \\
\text { 2. Operator dependency } \\
\text { 3. Potential violation of geometric assumption } \\
\text { in complex congenital heart diseases }\end{array}$ \\
\hline $\begin{array}{l}\text { Advanced } \\
\text { echocardiography }\end{array}$ & $\begin{array}{l}\text { 1. Reliable and reproducible assessment of myocardial } \\
\text { contractility and motion } \\
\text { 2. Independent of geometric assumptions, which is more } \\
\text { applicable in complex congenital heart disease } \\
\text { 3. Prognostication of newer parameters }\end{array}$ & $\begin{array}{l}\text { 1. Further longitudinal studies to validate } \\
\text { the prognostication of various new } \\
\text { echocardiographic parameters }\end{array}$ \\
\hline $\begin{array}{l}\text { Computed } \\
\text { tomography }\end{array}$ & $\begin{array}{l}\text { 1. Multi-planar reconstruction to delineate anatomy } \\
\text { in complex congenital heart disease } \\
\text { 2. Provision of extra-cardiac information }\end{array}$ & $\begin{array}{l}\text { 1. Radiation exposure } \\
\text { 2. Iodinated contrast } \\
\text { 3. Limitations in myocardial tissue characterization and } \\
\text { valvular/ shunt quantification }\end{array}$ \\
\hline $\begin{array}{l}\text { Magnetic resonance } \\
\text { imaging }\end{array}$ & $\begin{array}{l}\text { 1. Superior quantification of flows and shunts, and } \\
\text { characterization of myocardial tissue } \\
\text { 2. Provision of extra-cardiac information } \\
\text { 3. No radiation exposure }\end{array}$ & $\begin{array}{l}\text { 1. Longer examination time, and requirement for } \\
\text { sedation } \\
\text { 2. Contraindicated in certain groups of patients }\end{array}$ \\
\hline
\end{tabular}


ultrasonic image. Subsequently, strain has been measured using speckle tracking techniques $[19,20]$. Speckle tracking allows the calculation of strain, strain rate, and $2 \mathrm{D}$ tissue velocity. This novel study of myocardial motion represents a noninvasive method of definition of vectors and velocity [21].

Pixel tracking is another new echocardiographic technique that quantitatively analyzes segmental myocardial function by tracking natural acoustic markers in 2D echocardiography. It enables accurate analysis of regional systolic LV function by the frame to frame tracking of acoustic markers in 2D echocardiographic images in analyzing myocardial deformation [22].

Velocity vector imaging is a new quantitative echocardiographic modality. It quantifies LV mechanical dyssynchrony and predicts response to cardiac resynchronization therapy. Tissue velocities can be determined through automated tracking of Bmode image patterns from standard apical 2-chamber, 4-chamber, and long axis views. This technique can be used to accurately recognize and quantify abnormalities of regional myocardial deformation [23].

Besides, three-dimensional (3D) echocardiography has become an easily applicable clinical technique in recent years. The concept of 3D echocardiography is based on the transmission and reception of sound waves in mutually perpendicular planes, and forms a pyramid-shaped ultrasound beam. With this technology, 3D echocardiography can evaluate cardiac chamber volumes directly without the need for geometric modeling and without the detrimental effects of foreshortened apical views, resulting in more accurate and more reproducible LV volume and function measurements compared with $2 \mathrm{D}$ echocardiography [24]. When compared with 2D echocardiography, 3D echocardiography provides new "surgical" views of cardiac valves, adjacent structures, and intracardiac masses [24,25]. It has its own advantages when compared with other imaging modali- ties, as it does not have any contraindications in cases when used in pregnant women, children, the elderly, and in patients with implanted pacemakers.

\section{COMPUTED TOMOGRAPHY}

Computed tomography (CT), including CT angiography, plays an increasingly important role in the diagnosis and evaluation of patients with CHD. Compared with the older generations of CT scanners, newer scanners provide images with better temporal and spatial resolution, more anatomic coverage per rotation, more consistent contrast enhancement, and higher-quality $2 \mathrm{D}$ reformation and $3 \mathrm{D}$ reconstruction with acquisition of an isotropic data set $[26,27]$. These provide invaluable information for systematical delineation of the normal and pathologic morphologic features of the cardiovascular system. It can be used to systematically analyze the visceral situs, cardiac chambers and ventriculoarterial connection, aorta and coronary arteries, relationship between the upper lobe bronchi and pulmonary arteries, heart valves and systemic veins [28]. In patients with Ebstein anomaly, CT can demonstrate the morphology and location of tricuspid valves clearly, which helps surgeons planning for surgery (Fig. 1). Complex anatomy in condition such as double-outlet right ventricle can also be well demonstrated CT, with multiplanar reformat and 3D reconstruction of images (Fig. 2). This modality is exceptionally useful in understanding the anatomy of the cardiovascular system in CHD patients. It is also used in follow-up studies of post-operative patients who are contraindicated for MRI (Fig. 3).

However, CT may be technically challenging and demanding when dealing with uncooperative young children. Sedation or even anesthesia is still required for specific indications in young or critically ill CHD patients who are unable to cooperate.
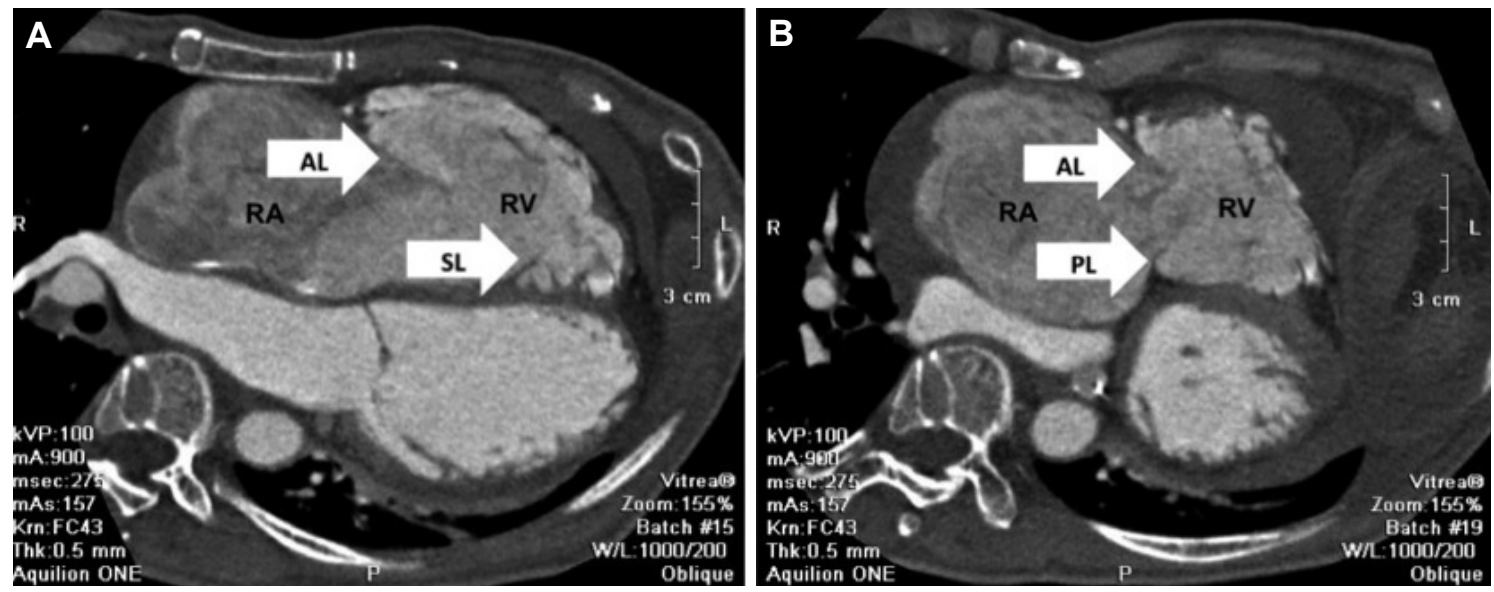

Fig. 1. Ebstein anomaly in a 15 year-old boy, who presented with decreased exercise tolerance and enlarged cardiac shadow on chest radiograph. Serial CT shows dilated right atrium (RA) and right ventricle (RV), with apical displacement of the mildly dysplastic septal leaflet (SL) of tricuspid valves, causing atrialization of RV (A), whereas anterior and posterior leaflets of tricuspid valves are undisplaced (B). AL: anterior leaflet, PL: posterior leaflet. 

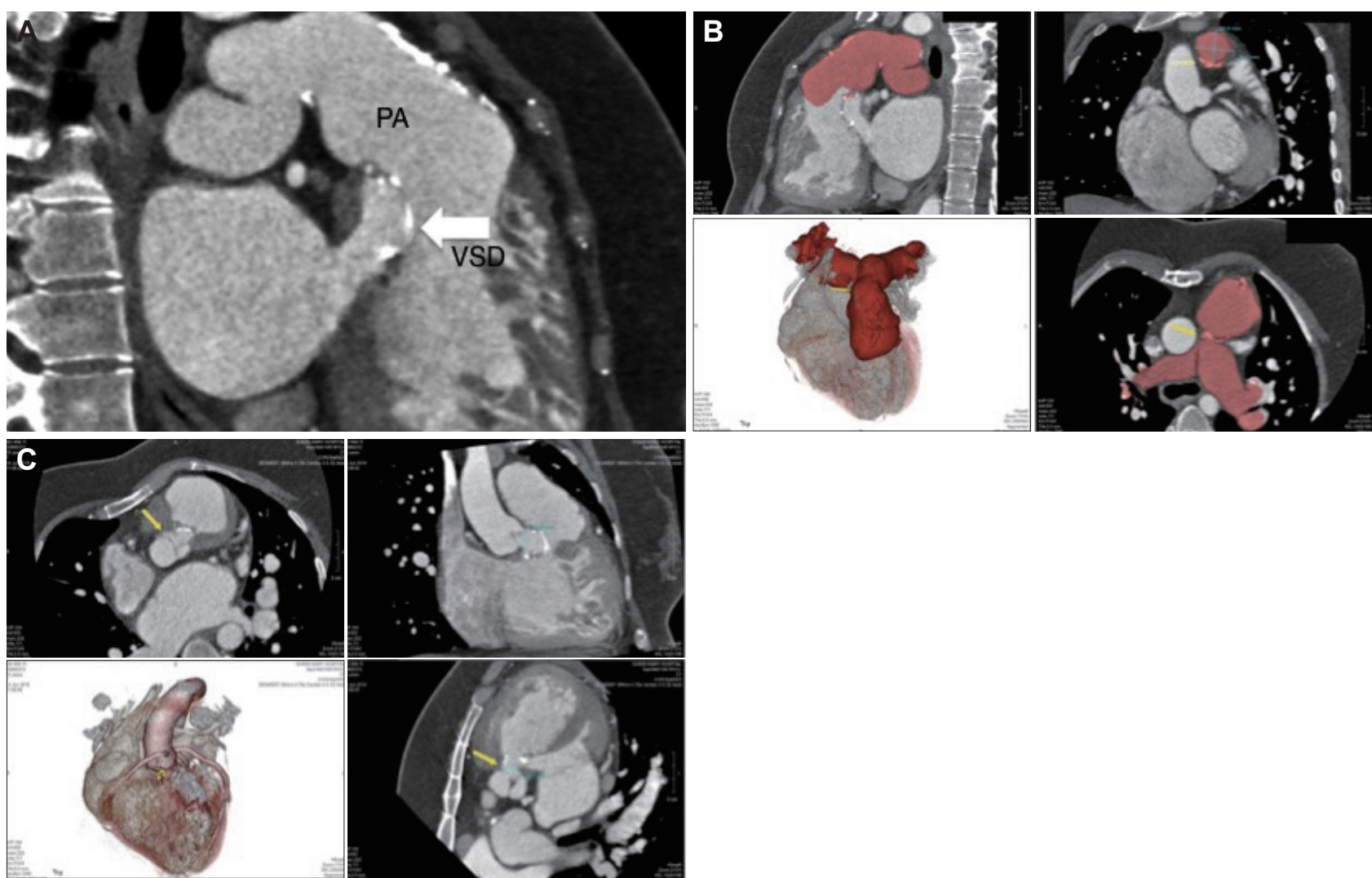

Fig. 2. Double-outlet right ventricle in a 14 year-old girl, who presented with increased shortness of breath. (A) Multiplanar reformat CT shows both pulmonary artery (PA) and aorta (Ao) arising from right ventricle, with residual subaortic ventricular septal defect (VSD, blue line and white arrow) on this multiplanar reformat of CT image. Previous banding of pulmonary artery (yellow arrow in B) and subvalvular aortic stenosis (yellow arrow in C) can been assessed in multiple angles and surgical views on multiplanar reformat CT, which cannot be achieved by echocardiography or conventional cardiac catheterization.

Limitations of cardiovascular CT also include limited myocardial tissue characterization, inability to quantify valve regurgitation in patients with more than one regurgitant lesion or shunt, intravenous administration of iodinated contrast and radiation exposure [29]. CT has both advantages and disadvantages in evaluating patients with CHD. Nevertheless, it is useful in this setting, and radiologists who perform CT in young children with CHD should be familiar with not only the advantages and disadvantages of CT but also the normal anatomy and typical pathologic conditions in affected patients.

\section{MAGNETIC RESONANCE IMAGING}

Magnetic resonance imaging (MRI) has emerged as an important tool in the evaluation of CHDs, pre-operative surgical planning, prognostication of patients, and post-operative surveillance [30,31]. MRI carries several advantages over echocardiography in imaging of $\mathrm{CHD}$. It is neither affected by geometrical assumptions applied in echocardiography, in particular in distorted and altered ventricular morphology in CHDs and postoperative cases; nor limited by acoustic window and scarring. Currently MRI has become the gold standard in assessing the ventricular function and volumes, delineating intracardiac anatomy and extracardiac vasculatures, quantifying shunts and flow volumes, and detecting myocardial fibrosis or scar tissue. Therefore MRI has surpassed echocardiography and catheterization in providing anatomical and physiological information on CHD, and has been recommended for paediatric patients in whom clinical or echocardiographic data is insufficient for surveillance and pre-operative planning [31].

Taking TOF as example, MRI has a superb role in post-operative surveillance and prognostication in this most common complex CHD in Hong Kong. The major long-term complication in patients after surgical repair of TOF is pulmonary regurgitation, in which its severity and prevalence increase with time. The contribution of impaired right ventricular mechanics and fibrosis on the pathophysiology of pulmonary regurgitation is understood to a great extent after the application of MRI. Surgical pulmonary valve replacement is now the standard procedure for treating pulmonary regurgitation in Hong Kong [32]. Though carrying low surgical mortality ( $0 \%$ in 6 year-period by Tsang et al. [32]), careful patient selection for the operation is essential to balance the benefits of reduction of right ventricular volumes and potential improvement of maximum oxygen consumption, 

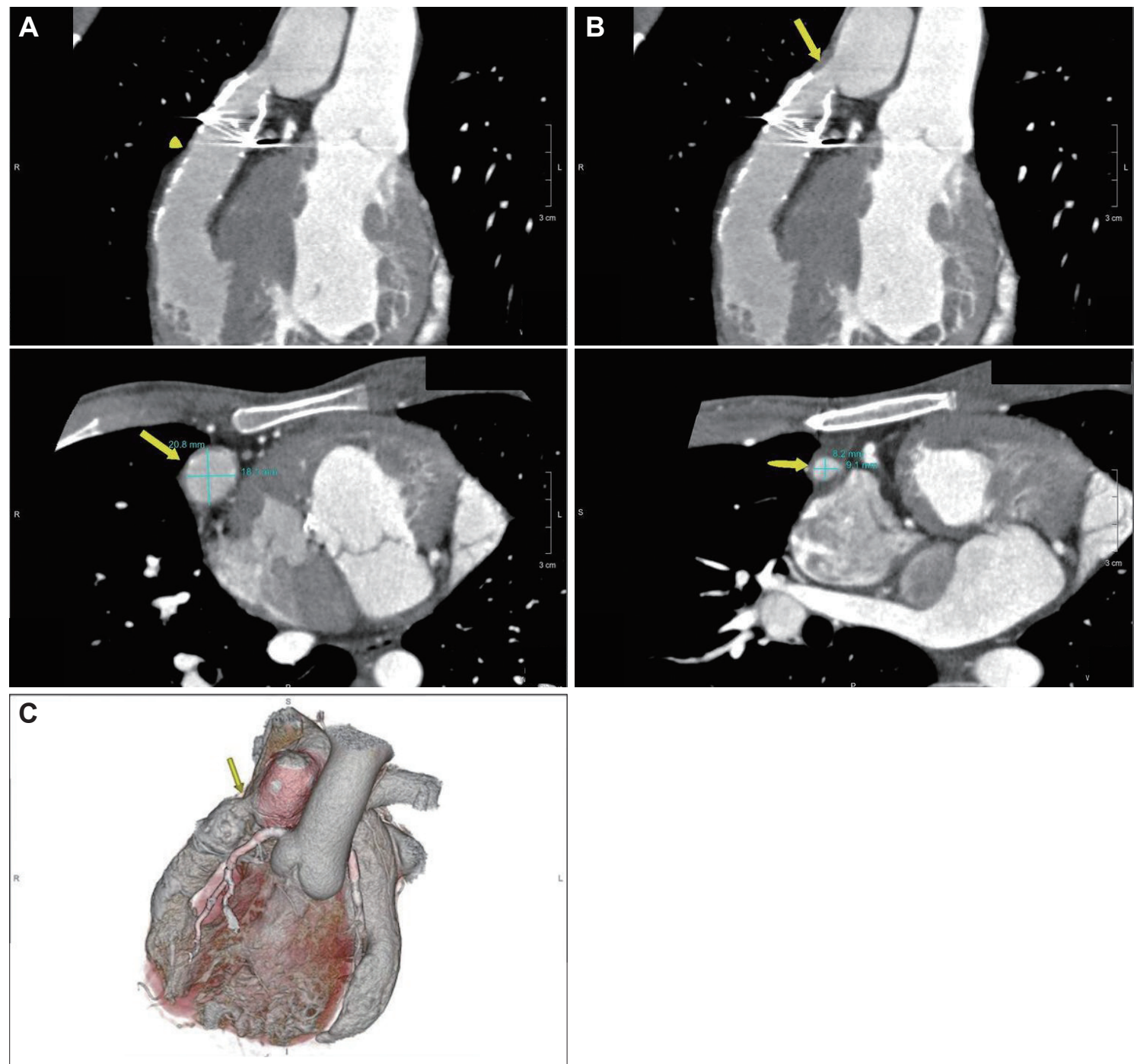

Fig. 3. Complex congenital heart disease with congenitally corrected transposition of great arteries and pulmonary atresia in a 15 year-old boy who had undergone stenting of right ventricular outflow tract (RVOT) due to repeated stenosis of reconstructed RVOT. The patency of the conduit was assessed by CT study, due to artefacts from stenting materials in MRI. Stented portion of the conduit (yellow arrow) is proven to be patent in CT. The yellow arrow indicates normal-caliber RVOT segment (indicated in A) on 2-chamber CT and axial scans. Distal to the stent, the yellow arrow indicates focal stenosis at RVOT segment (indicated in B) on 2-chamber CT and axial scans. (C) Volume rendering image indicates the focal stenosis (yellow arrow).
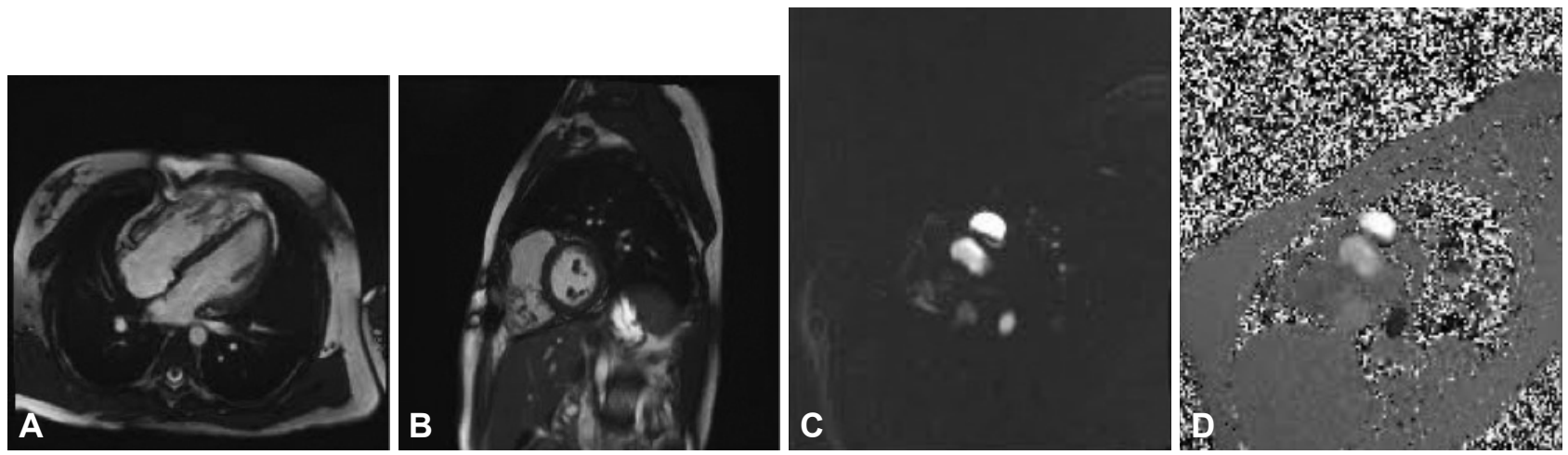

Fig. 4. Repaired tetralogy of Fallot in 11-year-old girl. Cardiac MR Axial image (A) and short axis (B) demonstrated mildly dilated right ventricle (RV) with mild myocardial hypertrophy and increased trabeculation. Functional analysis demonstrated mildly impaired RV function (RVEF 35.95\%) and satisfactory LV function (LVEF 56.73\%) (not shown). (C and D) Phase contrast flow analysis at main pulmonary artery suggested mild to moderate pulmonary regurgitation at regurgitation fraction at $28 \%$. 
against the risk of long-term anticoagulation and future re-operation $[33,34]$. Asymptomatic patients at high risk of sudden death, including right ventricular enlargement or dysfunction, arrhythmias and prolonged QRS duration, are referred for pulmonary valve replacement in Hong Kong [32]. MRI has been beckoned for identifying these patients, by evaluating bilateral ventricular volumes and ejection fraction, morphology of right ventricular outflow tract, and regurgitation flow volumes [32]. The prognostic values of other parameters, e.g., myocardial fibrosis and scarring as shown by late gadolinium enhancement,
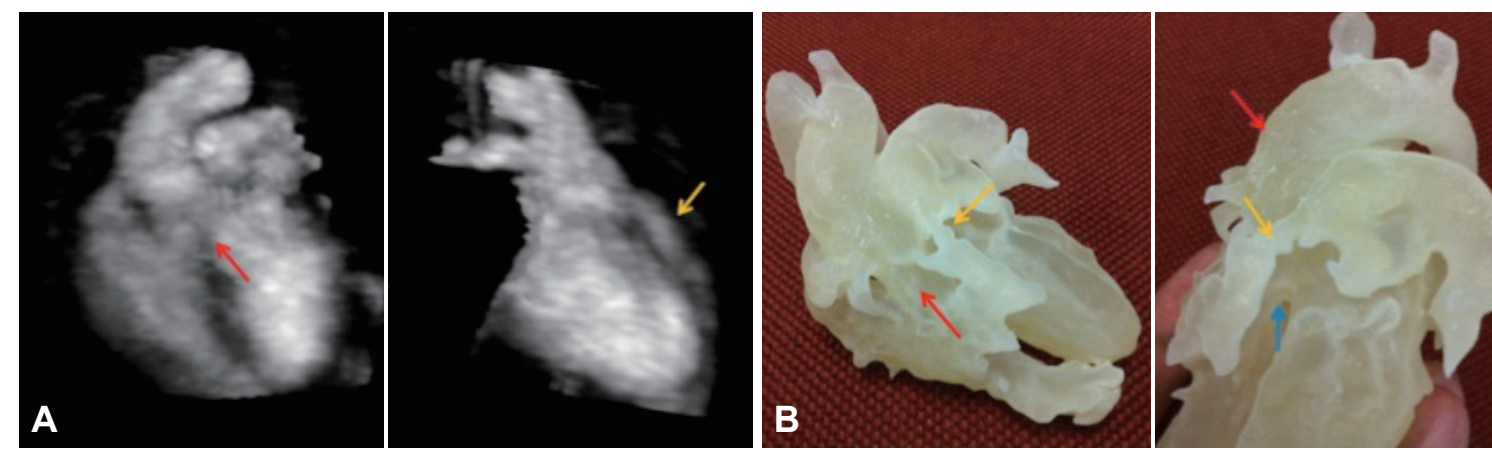

Fig. 5. Tetralogy of Fallot in a 1-year-old patient body. (A) Cardiac MR. Maximum intensity projection images from MRA show overriding aorta (red arrow) and narrowing of the right ventricular outflow tract (orange arrow). (B) 3D printing model. 3D model shows overriding aorta (red arrow), narrowed right ventricular outflow tract (orange arrow) and ventricular septal defect (blue arrow).
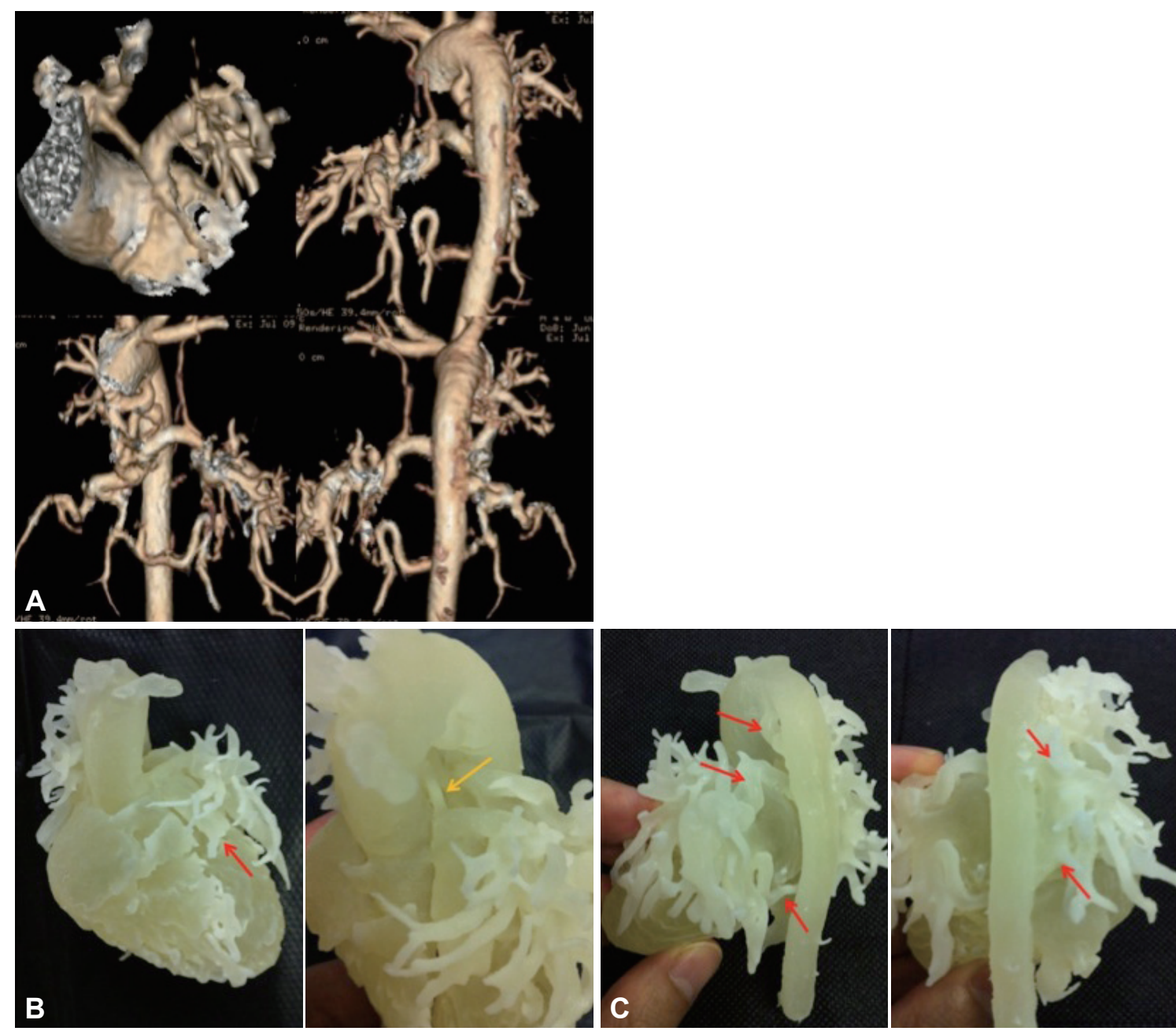

Fig. 6. Pulmonary atresia with ventricular septal defect in a 3-year-old boy. (A) Cardiac CT angiogram. 3D volume rendering images shows pulmonary atresia with a very narrow right pulmonary artery and multiple aortopulmonary collaterals arising from the aorta. (B) 3D printing model. 3D model shows the atretic pulmonary trunk (red arrow) and narrowed right pulmonary artery (orange arrow). (C) 3D printing model. 3D model shows multiple aortopulmonary collaterals to both lungs (red arrows). 

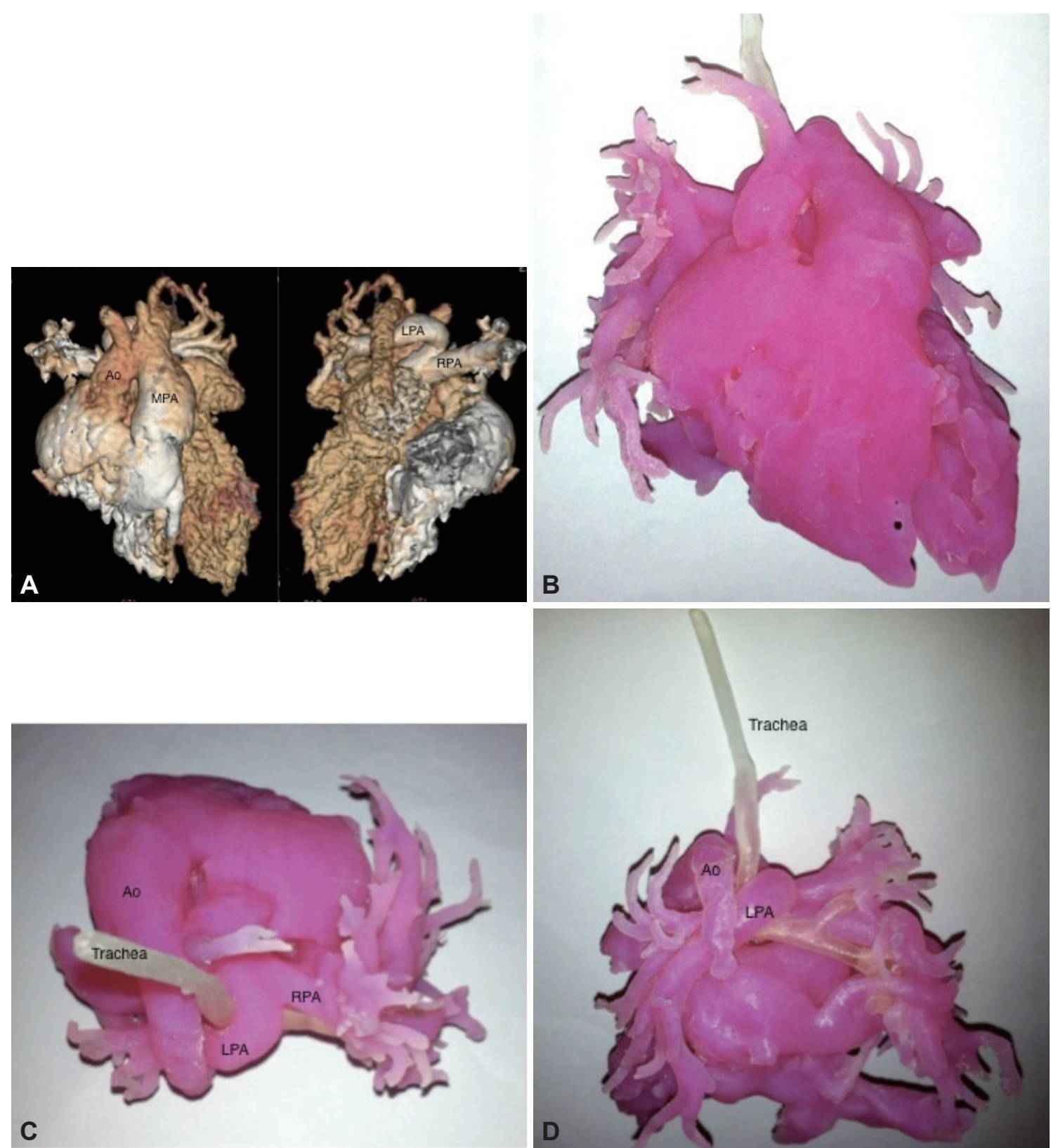

Fig. 7. Co-existence of aortopulmonary window (AP window) and left pulmonary artery sling in a 5-day-old neonate. (A) CT Angiogram. 3D volume rendering images demonstrate connection between main pulmonary artery and ascending aorta and LPA sling. (B) 3D printing model. 3D model shows the AP window. ( $C$ and $D$ ) 3D printing model. 3D models show the relationship of the airway to the LPA sling. Ao: aorta, MPA: main pulmonary artery, LPA: left pulmonary artery, RPA: right pulmonary artery.

on arrhythmia and impaired clinical outcomes also provide a guide in managing these post-TOF repair patients [35,36] (Fig. 4).

\section{D PROTOTYPING AND MODELING}

The use of 3D prototyping and modeling in Medicine is becoming increasingly important, due to the development of 3D printing and the recent rapid advances in relevant techniques and materials. With the advancement of industrial engineering in the arena of 3D printing, 3D models of heart and great vessels can be generated from high-resolution CT and MRI images. The use of 3D model is especially important in the field of paediatric cardiology and $\mathrm{CHD}$, where there is a clear advantage over conventional 2D images in demonstrating complex anatomies and relationships between different structures. It has become an established tool to assist in diagnostics, educational purposes and intervention planning. It is also proved to be an ideal way to visualize the complex structures in an accurate, realistic, and tangible way (Figs. 5, 6, and 7). 


\section{CONCLUSION}

The application of non-invasive imaging modalities has provided an insight in the understanding of the pathophysiology of CHDs, and allowed accurate and proper diagnosis, treatment planning and surveillance for these patients.

\section{Conflicts of Interest}

The authors declare that they have no conflict of interest.

\section{REFERENCES}

1. Dolk H, Loane M, Garne E; European Surveillance of Congenital Anomalies (EUROCAT) Working Group. Congenital heart defects in Europe: prevalence and perinatal mortality, 2000 to 2005. Circulation 2011; 123:841-849.

2. van der Linde D, Konings EE, Slager MA, Witsenburg M, Helbing WA, Takkenberg JJ, et al. Birth prevalence of congenital heart disease worldwide: a systematic review and meta-analysis. J Am Coll Cardiol 2011;58: 2241-2247.

3. Yeh SJ, Chen HC, Lu CW, Wang JK, Huang LM, Huang SC, et al. Prevalence, mortality, and the disease burden of pediatric congenital heart disease in Taiwan. Pediatr Neonatol 2013;54:113-118.

4. Sung RY, So LY, Ng HK, Ho JK, Fok TF. Echocardiography as a tool for determining the incidence of congenital heart disease in newborn babies: a pilot study in Hong Kong. Int J Cardiol 1991;30:43-47.

5. Jacobs EG, Leung MP, Karlberg J. Distribution of symptomatic congenital heart disease in Hong Kong. Pediatr Cardiol 2000;21:148-157.

6. Davies DP. Paediatric illness in Hong Kong and Britain. Arch Dis Child 1992;67:543-549.

7. Qu Y, Liu X, Zhuang J, Chen G, Mai J, Guo X, et al. Incidence of congenital heart disease: the 9-year experience of the guangdong registry of congenital heart disease, China. PLoS One 2016;11:e0159257.

8. Jacobs EG, Leung MP, Karlberg J. Birthweight distribution in southern Chinese infants with symptomatic congenital heart disease. J Paediatr Child Health 2003;39:191-196.

9. Jacobs EG, Leung MP, Karlberg JP. Postnatal growth in southern Chinese children with symptomatic congenital heart disease. J Pediatr Endocrinol Metab 2000;13:387-401.

10. van der Bom T, Bouma BJ, Meijboom FJ, Zwinderman AH, Mulder BJ. The prevalence of adult congenital heart disease, results from a systematic review and evidence based calculation. Am Heart J 2012;164:568-575.

11. Holling HE, Zak GA. Cardiac catheterization in the diagnosis of congenital heart disease. Br Heart J 1950;12:153-182.

12. Mehta R, Lee KJ, Chaturvedi R, Benson L. Complications of pediatric cardiac catheterization: a review in the current era. Catheter Cardiovasc Interv 2008;72:278-285.

13. Lee KE, Seo YJ, Kim GB, An HS, Song YH, Kwon BS, et al. Complications of cardiac catheterization in structural heart disease. Korean Circ J 2016;46:246-255.

14. Leung MP, Cheung DL, Lo RN, Mok CK, Lee J, Yeung CY. The management of symptomatic neonates with suspected congenital heart disease using combined cross-sectional echocardiography and pulsed Doppler flow study as the definitive investigations. Int J Cardiol 1989;24:41-46.

15. Leung MP, Mok CK, Lau KC, Lo R, Yeung CY. The role of cross sectional echocardiography and pulsed Doppler ultrasound in the management of neonates in whom congenital heart disease is suspected. A prospective study. Br Heart J 1986;56:73-82.

16. Leung MP, Mok CK, Hui PW. Echocardiographic assessment of neonates with pulmonary atresia and intact ventricular septum. J Am Coll Cardiol 1988;12:719-725.

17. Lau KC, Mok CK, Lo RN, Leung MP, Leung CY. Balloon atrial septostomy under two-dimensional echocardiographic control. Pediatr Cardiol
1987;8:35-37.

18. Cheung YF, Leung MP, Lee J, Yung TC. An evolving role of transesophageal echocardiography for the monitoring of interventional catheterization in children. Clin Cardiol 1999;22:804-810.

19. D’hooge J, Konofagou E, Jamal F, Heimdal A, Barrios L, Bijnens B, et al. Two-dimensional ultrasonic strain rate measurement of the human heart in vivo. IEEE Trans Ultrason Ferroelectr Freq Control 2002;49:281-286.

20. Reisner SA, Lysyansky P, Agmon Y, Mutlak D, Lessick J, Friedman Z. Global longitudinal strain: a novel index of left ventricular systolic function. J Am Soc Echocardiogr 2004;17:630-633.

21. Amundsen BH, Crosby J, Steen PA, Torp H, Slørdahl SA, Støylen A. Regional myocardial long-axis strain and strain rate measured by different tissue Doppler and speckle tracking echocardiography methods: a comparison with tagged magnetic resonance imaging. Eur J Echocardiogr 2009;10:229-237.

22. Becker M, Bilke E, Kühl H, Katoh M, Kramann R, Franke A, et al. Analysis of myocardial deformation based on pixel tracking in two dimensional echocardiographic images enables quantitative assessment of regional left ventricular function. Heart 2006;92:1102-1108.

23. Chen J, Cao T, Duan Y, Yuan L, Wang Z. Velocity vector imaging in assessing myocardial systolic function of hypertensive patients with left ventricular hypertrophy. Can J Cardiol 2007;23:957-961.

24. Thavendiranathan P, Liu S, Verhaert D, Calleja A, Nitinunu A, Van Houten T, et al. Feasibility, accuracy, and reproducibility of real-time full-volume 3D transthoracic echocardiography to measure LV volumes and systolic function: a fully automated endocardial contouring algorithm in sinus rhythm and atrial fibrillation. JACC Cardiovasc Imaging 2012;5:239-251.

25. Chan KL, Liu X, Ascah KJ, Beauchesne LM, Burwash IG. Comparison of real-time 3-dimensional echocardiography with conventional 2-dimensional echocardiography in the assessment of structural heart disease. J Am Soc Echocardiogr 2004;17:976-980.

26. Siegel MJ. Multiplanar and three-dimensional multi-detector row CT of thoracic vessels and airways in the pediatric population. Radiology 2003; 229:641-650.

27. Spevak PJ, Johnson PT, Fishman EK. Surgically corrected congenital heart disease: utility of 64-MDCT. AJR Am J Roentgenol 2008;191:854-861.

28. Khairy P, Van Hare GF, Balaji S, Berul CI, Cecchin F, Cohen MI, et al. PACES/HRS Expert Consensus Statement on the Recognition and Management of Arrhythmias in Adult Congenital Heart Disease: developed in partnership between the Pediatric and Congenital Electrophysiology Society (PACES) and the Heart Rhythm Society (HRS). Endorsed by the governing bodies of PACES, HRS, the American College of Cardiology (ACC), the American Heart Association (AHA), the European Heart Rhythm Association (EHRA), the Canadian Heart Rhythm Society (CHRS), and the International Society for Adult Congenital Heart Disease (ISACHD). Heart Rhythm 2014;11:e102-e165.

29. Han BK, Rigsby CK, Hlavacek A, Leipsic J, Nicol ED, Siegel MJ, et al. Computed Tomography Imaging in Patients with Congenital Heart Disease Part I: Rationale and Utility. An Expert Consensus Document of the Society of Cardiovascular Computed Tomography (SCCT): Endorsed by the Society of Pediatric Radiology (SPR) and the North American Society of Cardiac Imaging (NASCI). J Cardiovasc Comput Tomogr 2015;9: 475-492.

30. Kilner PJ, Geva T, Kaemmerer H, Trindade PT, Schwitter J, Webb GD. Recommendations for cardiovascular magnetic resonance in adults with congenital heart disease from the respective working groups of the European Society of Cardiology. Eur Heart J 2010;31:794-805.

31. Ntsinjana HN, Hughes ML, Taylor AM. The role of cardiovascular magnetic resonance in pediatric congenital heart disease. J Cardiovasc Magn Reson 2011;13:51.

32. Tsang FH, Li X, Cheung YF, Chau KT, Cheng LC. Pulmonary valve replacement after surgical repair of tetralogy of Fallot. Hong Kong Med J 2010;16:26-30.

33. Geva T. Indications and timing of pulmonary valve replacement after tetralogy of Fallot repair. Semin Thorac Cardiovasc Surg Pediatr Card Surg 
Annu 2006;9:11-22.

34. Tsang FH, Wong SJ, Cheung YF. Pulmonary valve replacement and quality-of-life assessment. Asian Cardiovasc Thorac Ann 2016;24:5-11.

35. Park SJ, On YK, Kim JS, Park SW, Yang JH, Jun TG, et al. Relation of fragmented QRS complex to right ventricular fibrosis detected by late gadolinium enhancement cardiac magnetic resonance in adults with re- paired tetralogy of Fallot. Am J Cardiol 2012;109:110-115.

36. Babu-Narayan SV, Kilner PJ, Li W, Moon JC, Goktekin O, Davlouros PA, et al. Ventricular fibrosis suggested by cardiovascular magnetic resonance in adults with repaired tetralogy of fallot and its relationship to adverse markers of clinical outcome. Circulation 2006;113:405-413. 